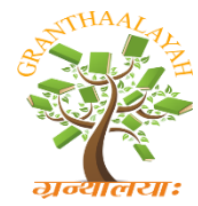

$$
\begin{aligned}
& \text { INTERNATIONAL JOURNAL OF RESEARCH - } \\
& \text { GRANTHAALAYAH } \\
& \text { A knowledge Repository }
\end{aligned}
$$

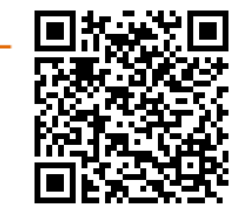

Science

\title{
BUTLER MATRIX IN MICROSTRIP-SLOT TECHNOLOGY
}

\author{
D.Rajeswari ${ }^{* 1}$, T.Jayanthy ${ }^{2}$ \\ ${ }^{*} 1,2$ Department of ECE, Panimalar Institute of Technology, Chennai,
}

India DOI: https://doi.org/10.29121/granthaalayah.v5.i4.2017.1820

\begin{abstract}
The design of a $4 \times 4$ Butler Matrix for use in a multi-beam antenna array operating over wide frequency band is presented. In order to achieve wideband characteristics, the matrix uses microstrip-slot technology that employs two microstrip dielectric layers with a common ground plane and a coupling slot. The designed Butler matrix is compact in size and does not use crossovers. Its prototype is manufactured. The performance of the designed device is assessed via full-wave electromagnetic simulations and measurements.
\end{abstract}

Keywords: Butler Matrix; UWB; Microstrip-Slot Coupler; Multilayer Technology.

Cite This Article: D.Rajeswari, and T.Jayanthy. (2017). "BUTLER MATRIX IN MICROSTRIP-SLOT TECHNOLOGY." International Journal of Research Granthaalayah, 5(4), 268-273. https://doi.org/10.29121/granthaalayah.v5.i4.2017.1820.

\section{Introduction}

The presence of multiple users and multi-path signal propagation contributes to co-channel interference and fading which degrade the quality of wireless communications. In order to reduce adverse effects of multi-user interference and multi-path, angle diversity is postulated as one of effective remedies [1,2]. This technique requires the use of array antennas at one or two sides of communication link. By transmitting signals in the direction of desired user and by placing nulls towards undesired directions, the effect of interference and multipath fading can be reduced. Also by employing array antennas on two sides of the communication link it is possible to tap to multiple virtual channels in rich scattering environments. The use of such multiple channels can improve diversity of the system or increase its capacity depending on the signal transmission strategy. Butler Matrix is one of the widely-known beam forming networks for use in switchedbeam antenna systems. Usually it operates over a narrow frequency band to maintain the specified beams directions. $\mathrm{N}$ orthogonal beams pointed at different angles can be generated in switched beam antenna system by connecting $\mathrm{N}$ x N Butler Matrix to N-element array antenna. As there is an increased demand on wireless communications to provide high data throughput [3], it is essential that Butler Matrix has to be operate over an increased frequency band when used for angle diversity. Recently a new class of ultra-wideband (UWB) systems for high speed 
wireless communications operating over frequency band from 1.0 to $10 \mathrm{GHz}$ has been introduced. A wideband Butler Matrix can be used in these systems to achieve transmit or receive diversity.

\section{Literature Review}

In the paper of Nhi T. Pham1, Gye-An Lee2 [1] stated that beam forming network with a multinarrow-beam antenna array for WLAN applications is presented. The antenna array has four inputs and is excited by the Butler matrix feeding network to electronically steer the beams in desired directions. The architecture of the Butler matrix beamforming network is analyzed with the considerations of coupling effects between fundamental elements of the network and the antenna array. An smart antenna system of 4-element microstrip linear array antenna with Butler matrix beam forming network is designed [12][2], analyzed and implemented using microstrip technology in completely planar structure without suffering from power losses or poor antenna pattern characteristics. The performance of this smart antenna system is analyzed and the beam forming features are monitored as function of geometrical antenna and Butler matrix parameters in the frequency from $1 \mathrm{GHZ}$ to $10 \mathrm{GHz}$. Smart antenna efficiency and directivity are improved and its side lobe level is enhanced which make it very promising. An Overview of Adaptive Antenna Technologies for Wireless Communication" [3] Smart antenna systems are rapidly emerging as one of the key technologies that can enhance overall wireless communications system performance. By making use of the spatial dimension, and dynamically generating adaptive receive and transmit antenna patterns, a smart antenna can greatly reduce interference, increase the system capacity, increase power efficiency as well as reduce overall infrastructure costs. In this paper the concept of the smart antenna is reviewed. The topic of multi-beam smart antenna array has been receiving much attention due to its wide range of applications. Different multi-beam antenna prototypes are implemented for the applications in base stations [5], [6] to improve the quality of transmission and enhance the cellular capacity, range, and coverage [7] because the antenna array is capable of pointing to desired targets automatically in real time. Moreover, the multipath fading and interferences phenomenon in communications systems can be solved using switched beam antenna array for rejecting interference signals and increasing desired signal level [5]. The system can produce multiple narrow beams in different directions and select the strongest signal among all of the available ones. The system can distinguish the users that stand at different positions, and as a result, expand the capacity [7]. Smart antennas can be characterized into two main categories: adaptive antenna array and switched beam system [3]. Compared with adaptive antenna arrays, switched beam systems have advantages in implementation because of its simplicity in the design.

As Jean-SébastienNéron and Gilles-Y.Delisle stated in the paper [4] Scientific studies based on indoor channel measurement campaigns have shown that highly directive antennas used at both the transmitter and receiver of a communication system can reduce considerably the delay spread of the signal reaching the receiver while at the same time improve the signal gain. Electronicallysteered phased arrays are well known for their ability to generate a directive beam according to a given control signal and may be a possible multipath mitigation solution. One way to implement this electronic scanning is by using electronically controlled phase shifters [8]. Another approach would be to generate a set of predefined beams and select among them the beam with satisfying properties [9]. A subset of these beams (or all of them) with proper weighting can also be 
combined in such a way that a desired array response is obtained. The latter alternative requires a beamforming network that transforms the signal from the $\mathrm{N}$ antenna elements to a predefined set of $\mathrm{M}$ beams.

\section{Butler Matrix}

A Butler beam forming matrix for a four element array is as show in fig.1. By tracing the signal from the four input ports to the array elements, here $4 \times 4$ butler matrix is considered for the paper. Here for construction of Butler matrix four number of quadreture coupler, two number of cross over coupler and two number of $45_{0}$ phase shifter. Brief design and analysis is disused in next part of this paper.

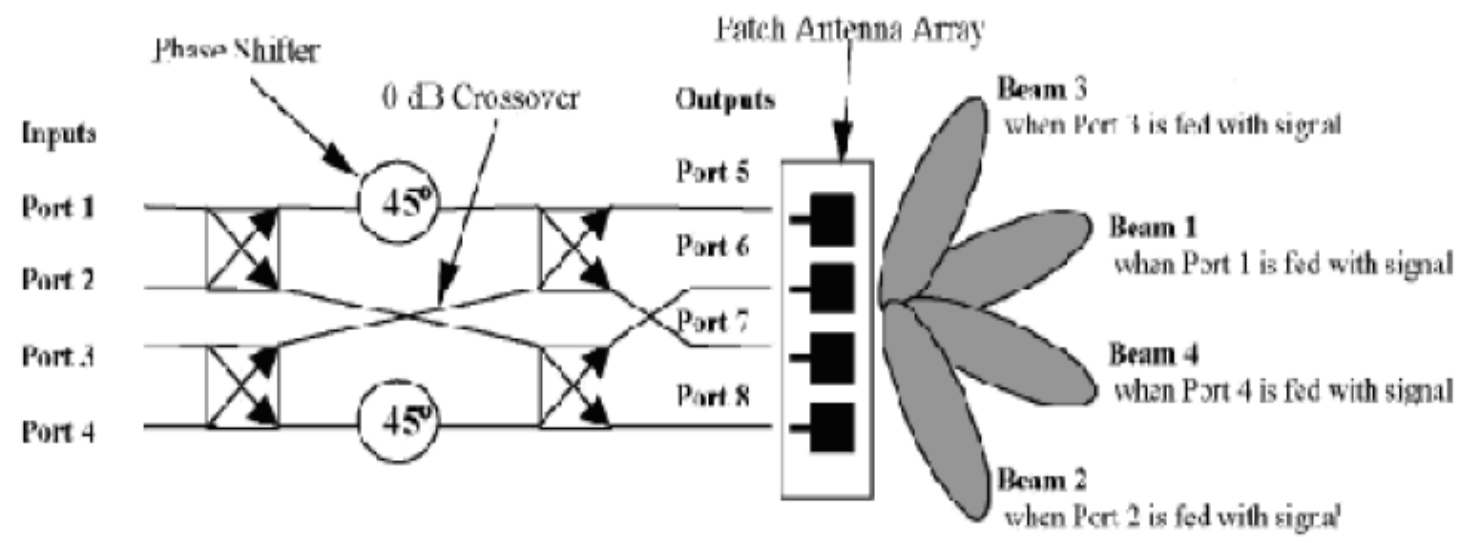

Figure 1: Block diagram of $4 \mathrm{X} 4$ butler matrix

\section{Design and Simulation}

The structure of beamforming network [10] with array elements is as shown in figure 1. This matrix generates a set of $\mathrm{N}$ orthogonal beams from the $\mathrm{N}$ antenna elements of an equispaced linear array. For simulation, though the data was considered for a range of 1.5 to $3 \mathrm{GHz}$ frequency, but the individual component designs were done at $2.4 \mathrm{GHz}$. The final design was done on FR4 board, with substrate height of $1.5 \mathrm{~mm}, \varepsilon \mathrm{r}=10.2, \tan \delta=0.0035$.

In this we simulate the Butler Matrix. The $\mathrm{N} \times \mathrm{N}$ Butler matrix creates a set of $\mathrm{N}$ orthogonal beams in space by processing the signal from the $\mathrm{N}$ antenna elements of an equispaced linear array. These beams are pointing in direction $\theta$ governed by the following equation [4]:

$$
\operatorname{Sin} \theta \mathbf{i}= \pm(i \lambda / 2 \mathrm{Nd})
$$

Where $i=1,2,3 \ldots(\mathrm{N}-1)$.

The corresponding inter element phase shift with spacing $d=\lambda / 2$ is

$$
\alpha \mathbf{i}=\beta \mathrm{d} \sin \theta \mathbf{i}=\mathrm{i}(\pi / \mathrm{N})
$$

Where $\beta=2 \pi / \lambda$, is the wave number. 
The optimum design of $4 \times 4$ planar Butler matrix array which consist of phase shifters. Butler matrix has four in-puts $1 \mathrm{R}, 2 \mathrm{~L}, 2 \mathrm{R}, 1 \mathrm{~L}$ and four outputs. These four outputs are used as inputs to antenna elements to produce four beams. The input ports of the Butler matrix are named according to their beam position.

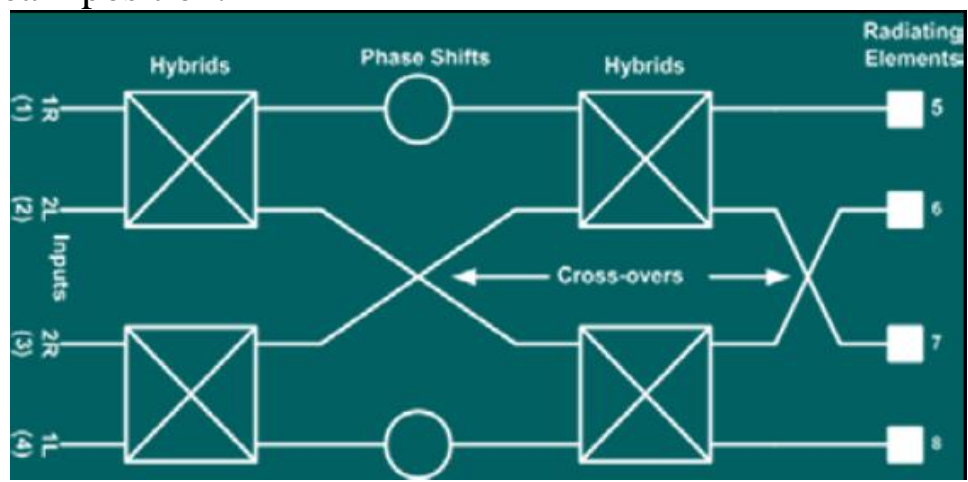

Figure 1: Structure of Butlermatrix fed array

\subsection{Microstrip Antenna}

The main radiating element in this proposed work is rectangular patch antenna. The microstrip antenna is Implemented Rogers RO3010 substrate with on planer substrate. The single patch antenna is designed, with an inset feed at a length of $33.33 \%$ of the total length. However when the array of four patches was placed together, it is observed that maximum radiated field obtained at normal to the structure surface. Hence to take care of this new problem of the fringing fields along the width, the patch length is extended on both sides by additional length given by,

$$
\mathrm{L}_{\text {eff }}=\mathrm{L}+2 \Delta \mathrm{L}
$$

where,

$\Delta \mathrm{L}=0.412 \mathrm{~h}\left(\varepsilon_{\text {reff }}+0.3\right)(\mathrm{W} / \mathrm{h}+0.264)$

$\left(\varepsilon_{\text {reff }}-0.258\right)(\mathrm{W} / \mathrm{h}+0.8)$

$\mathrm{L}_{\text {eff }}=\mathrm{c} / 2 \mathrm{f}_{\mathrm{osq}}$ rt ( $\left(\varepsilon_{\text {reff }}\right)$.

However the element spacing was kept constant throughout the four patch antennas [12].

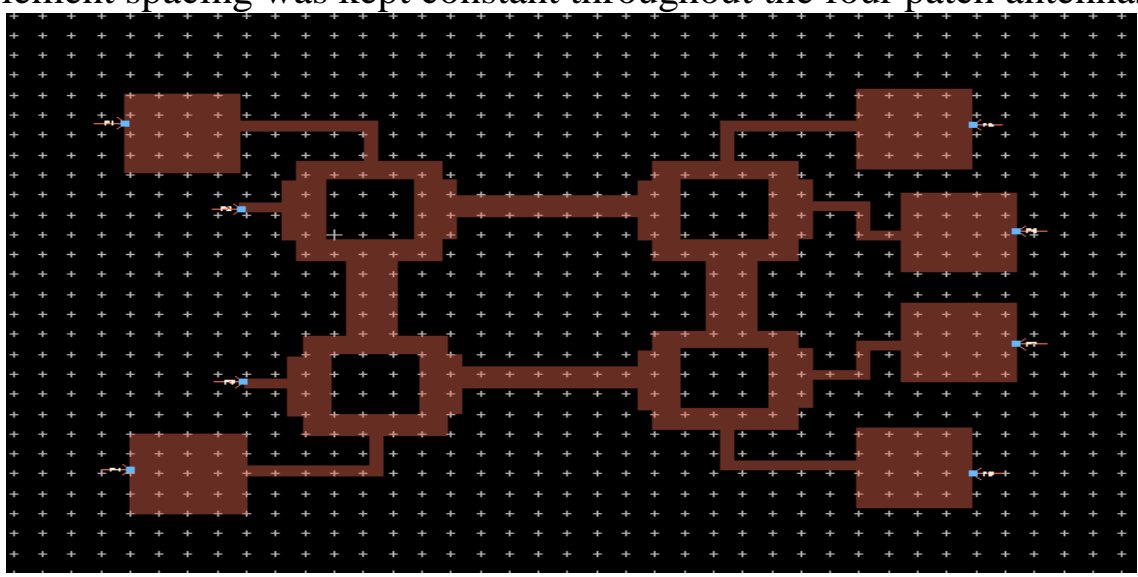

Figure 2: 4X4 butler matrix implemented 


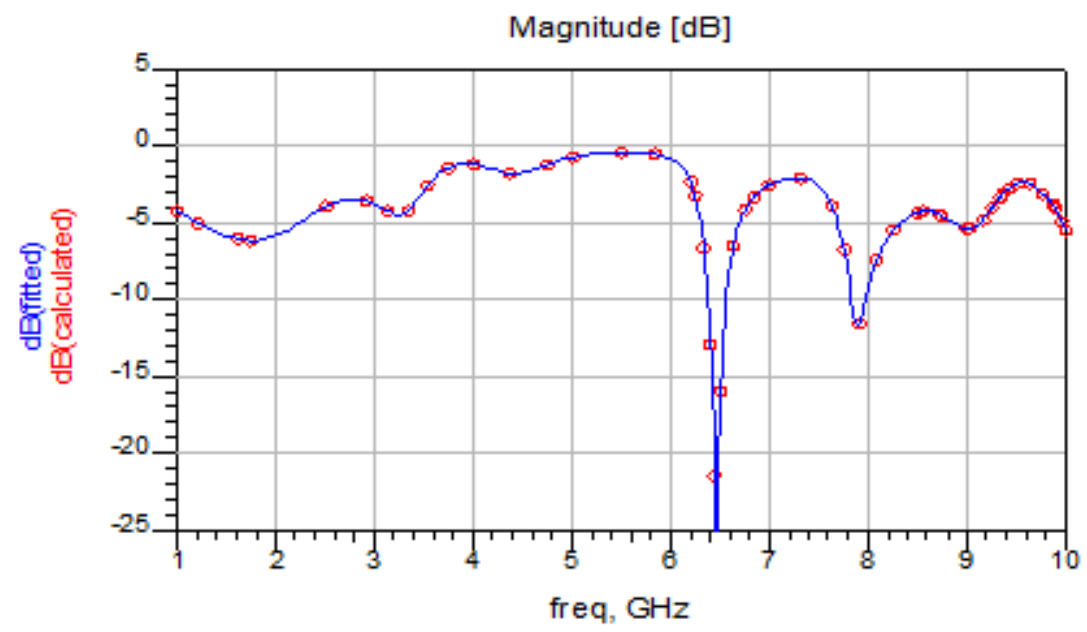

Figure 3: Simulated Return loss

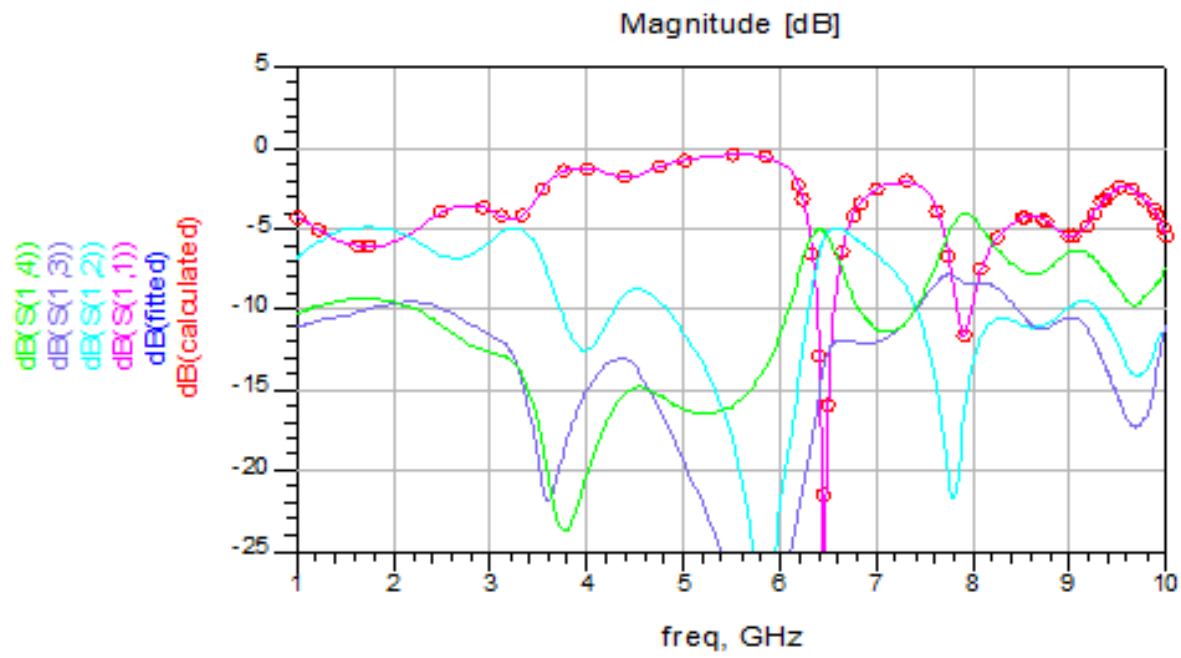

Figure 4: Frequency characteristics of the Slot Coupled Directional Coupler.

Table: 1 Summary of Results for Buttler Matrix

\begin{tabular}{|l|l|}
\hline Parameters & Results \\
\hline Return Loss (S11) & $-25 \mathrm{~dB}$ \\
\hline Isolation (S12) & $-5 \mathrm{~dB}$ \\
\hline Isolation (S13) & $-25 \mathrm{~dB}$ \\
\hline Isolation (S14) & $-20 \mathrm{~dB}$ \\
\hline Coupling (S15) & $-18 \mathrm{~dB}$ \\
\hline Coupling (S16) & $-30 \mathrm{~dB}$ \\
\hline Coupling (S17) & $-10 \mathrm{~dB}$ \\
\hline Coupling (S18) & $-13 \mathrm{~dB}$ \\
\hline Return Loss (S22) & $-22 \mathrm{~dB}$ \\
\hline Return Loss (S33) & $-25 \mathrm{~dB}$ \\
\hline Return Loss (S44) & $-17 \mathrm{~dB}$ \\
\hline
\end{tabular}




\section{Conclusion}

This paper presents design and simulation of a smart antenna system using microstrip antenna array with Butler matrix beamforming network for wireless applications. The basic configuration of a rectangular patch antenna array is observed to give a better performance at the mentioned operating frequency. The Butler matrix works as a perfect passive beam forming microwave network. The optimized design of hybrid and phase shifter has been achieved. The reflection, coupling, isolation effects of the individual design are studied and discussed. The isolation at the non-coupling port of the zero $\mathrm{dB}$ coupler is effectively achieved. The beam can be switched with a control over its progressive phase change.

\section{References}

[1] Microstrip Antenna Array with Beamforming Network for WLAN Applications Nhi T. Pham1, Gye-An Lee2, and Franco De Flaviis1Department of Electrical Engineering and Computer Science.

[2] M. El-Tager and M. A. Eleiwa Electronics Department, M. T. C., Cairo, Egypt Design and Implementation of a Smart Antenna Using Butler Matrix for ISM-band Progress In Electromagnetic Research Symposium, Beijing, China, March 23\{27, 2009\}

[3] CNSRC3, SESSION A3 Chris Loadman, Dr.ZhizhangChen, DylanJorgenssen,"An Over view of Antenna Technologies For Wireless Communication"

[4] Jean-SébastienNéron and Gilles-Y. DelisleETRIMicrostrip EHF Butler Matrix Design and Realization Jean-SébastienNéron and Gilles-Y. DelisleETRI Journal, Volume 27, Number 6, December 2005.

[5] Tayeb. A. Denidni and Taro Eric Libar, "Wide Band Four-Port Butler Matrix for Switched Multibeam Antenna Arrays," The 14th IEEE 2003 International Symposium on Personal, Indoor and Mobile Radio Communication Proceedings, pp.2461-2464, 2003.

[6] E. Siachalou, E. Vafiadis, Sotorios S, Goudos, T. Samaras, C. S. Koukourlis, and Stavros Panas, "On the Design of Switched-Beam Wideband Base Stations", IEEE Antennas and Propagation Magazine, Vol. 46, No. 1, pp. 158-167, February 2004.

[7] R. Comitangelo, D. Minervini, B. Piovano, "Beam Forming Networks of Optimum Size and Compactness for Multibeam Antennas at 900 MHz", IEEE Antenna and Propagation International Symposium, Vol. 4, pp. 2127-2130, July, 1997.

[8] M. J. Gans, R. A. Valenzuela, J. H. Winters, and M. J. Carloni, "High Data Rate Indoor Wireless Communications Using Antenna Arrays," Sixth IEEE Int'l Symp. Personal, Indoor and Mobile Radio Communications, Toronto, Canada, 1995, pp. 1040-1046

[9] P. F. Driessen, "Gigabit/s Indoor Wireless Systems with Directional Antennas," IEEE Transactions on Communications, vol. 44, Aug.1996, pp. 1034-1043.

[10] J. L. Butler, "Digital, Matrix and Intermediate-Frequency Scanning," Microwave Scanning Antennas, R. Hansen, ed., Academic press, New York, vol. 3, 1966, pp. 217-288.

[11] Planar Implementation of Butler Matrix feed network for a switched Author: Ajay P. Thakare, MIEEE, FIETE, FIE (I), MISTE.

[12] WriddhiBhowmik and ShwetaSrivastava, "Optimum Design of a 4x4 Planar Butler Matrix Array for WLAN Application", Journal Telecommunication Volume 2 Page-68-74, Volume-April2010 .

*Corresponding author.

E-mail address: rajeswariece148@gmail.com 